\title{
Use of continuous-elution gel electrophoresis as a preparative tool for blot overlay analysis
}

\author{
Claire Mulvey $^{\mathrm{a}}$ and Kay Ohlendieck ${ }^{\mathrm{b}, *}$ \\ a Department of Pharmacology, University College Dublin, Belfield, Dublin 4, Ireland \\ ${ }^{\mathrm{b}}$ Department of Biology, National University of Ireland, Maynooth, Co. Kildare, Ireland
}

Received 27 February 2003

\begin{abstract}
Blot overlay techniques have long been used to directly visualize protein-protein interactions within membrane complexes. However, this approach is often hampered by the limited quantities of purified membrane proteins available for conjugation with marker molecules. Here we applied continuous-elution gel electrophoresis as a preparative alternative to isolate sufficient amounts of a homogenous protein sample to be used as a peroxidase-labeled probe in blot overlays. Microsomal muscle proteins ranging from approximately 20 to $600 \mathrm{kDa}$ were electrophoretically separated and various marker proteins present in eluted fractions were identified by immunoblotting. Since the supramolecular structure of calsequestrin has recently been determined, this terminal cisternae protein was isolated as a model protein for studying protein-protein interactions. In blot overlay assays, peroxidase-conjugated calsequestrin specifically bound to the ryanodine receptor, triadin, calsequestrin itself, and junctin, illustrating that the biological binding affinities are retained in electrophoretically prepared muscle proteins. Potential applications for differential blot overlay approaches and for analyzing pathophysiological preparations from dystrophic muscle were evaluated. Since continuouselution gel electrophoresis can separate a wide range of differently sized proteins from subcellular fractions, our report indicates that this technique can be utilized for the rapid identification of protein-protein interactions in future high-throughput analyses of subproteomes.
\end{abstract}

(C) 2003 Elsevier Science (USA). All rights reserved.

Keywords: Blot overlay; Calsequestrin; Continuous-elution gel electrophoresis; Protein oligomerization; Supramolecular complex

If a protein species can be isolated in sufficient amounts for proper conjugation to a marker molecule such as peroxidase, blot overlay procedures can be used to directly determine potential self-aggregation patterns and/or high binding affinities for other cellular components [1-3]. Due to the many preparative steps involved, blot overlays are a technically challenging approach whereby the sensitivity of detection is of crucial importance. The introduction of enhanced chemiluminescence as applied to blot overlay techniques has decisively advanced the limits of protein detection [4]. Although at the current state of optimization, the decoration of proteins via peroxidase-labeled probes does not result in the same degree of linear signaling achieved by immunoblot analysis, this does not limit the range of potential

\footnotetext{
* Corresponding author. Fax: +353-1-708-3845.

E-mail address: kay.ohlendieck@may.ie (K. Ohlendieck).
}

biochemical applications of the blot overlay approach. In addition to electron microscopy and native gel electrophoresis, it is the only established method of directly visualizing protein linkage making it extremely useful for the initial identification of complex protein-protein interactions between different elements of a heterogeneous membrane assembly.

Results from blot overlay assays in conjunction with data obtained by size-exclusion chromatography, chemical cross-linking analysis, differential coimmunoprecipitation experiments, copurification analysis, electron microscopy, analytical ultracentrifugation, blue native gel electrophoresis, and domain binding studies have demonstrated that under native conditions many biological macromolecules exist in supramolecular assemblies [5-8]. A well-established example of a highly oligomerized protein assembly is represented by the $\mathrm{Ca}^{2+}$-release complex of the junctional triads from 
skeletal muscle fibers [9-11]. Protein-protein interactions between the ryanodine receptor, triadin, junctin, and the $\mathrm{Ca}^{2+}$-binding protein calsequestrin form the functional basis of the regulatory apparatus that mediates $\mathrm{Ca}^{2+}$ release during excitation-contraction coupling $[12,13]$. We have recently established a calsequestrin blot overlay assay using conventional chromatography techniques for the isolation of this terminal cisternae marker [14] and have shown the usefulness of this technique in studying changes in protein-protein interactions under different physiological conditions [15]. Variations in the relative abundance of the four central elements of excitation-contraction coupling in different fiber types and during chronic electrostimulation-induced fiber-type transitions were shown to be reflected by distinct alterations in the calsequestrin overlay binding patterns [15].

One obstacle for the development of high-throughput approaches for the rapid identification of protein-protein interactions within subproteomes is often the limited amount of individual protein species available that can be isolated to homogeneity by conventional chromatography. Here we have applied continuous-elution gel electrophoresis as a preparative alternative to isolate sufficient amounts of calsequestrin to use it as a peroxidase-labeled probe in a blot overlay assay. Preparative gel electrophoresis of skeletal muscle microsomes was employed to conveniently separate and elute solubilized membrane proteins ranging from approximately 20 to $600 \mathrm{kDa}$. In blot overlay assays, peroxidase-conjugated calsequestrin specifically bound to itself, junctin, triadin, and the $\mathrm{Ca}^{2+}$-release channel, which strongly suggests that the biological binding affinities of calsequestrin are retained following preparative gel electrophoresis. Thus, this study sets the scene for developing a new proteomics-type strategy for the global determination of protein-protein interactions, combining continuous-elution gel electrophoresis with blot overlay techniques.

\section{Materials and methods}

\section{Materials}

Chemiluminescence substrates, the EZ-Link-Plus Activated Peroxidase Kit, Slide-A-Lyzer Dialysis Cassettes, the Seize-X Protein A immunoprecipitation kit and SDS-OUT Precipitation Kit were from Perbio Science UK (Tattenhall, Cheshire, UK). Primary antibodies to marker proteins were obtained from Affinity Bioreagents (Golden, CO), Upstate Biotechnology (Lake Placid, NY), Chemicon International (Temecula, CA), and Novacastra Laboratories (Newcastle upon Tyne, UK). Peroxidase-conjugated secondary antibodies were from Chemicon International and protease in- hibitors were purchased from Boehringer-Mannheim (Lewes, East Sussex, UK). Ultrapure Protogel acrylamide stock solutions were from National Diagnostics (Atlanta, GA). Immobilon P nitrocellulose and Ultrafree filter units were from Millipore (Bedford, MA). All general chemicals for protein purification and electrophoretic separation were of analytical grade and supplied by Sigma (Poole, Dorset, UK).

\section{Microsomal membrane preparation}

All procedures were carried out at $4{ }^{\circ} \mathrm{C}$ in the presence of a protease inhibitor cocktail $(0.2 \mathrm{mM}$ pefabloc, $1.4 \mu \mathrm{M}$ pepstatin A, $0.3 \mu \mathrm{M}$ E-64, $1 \mu \mathrm{M}$ leupeptin, $1 \mathrm{mM}$ EDTA, and $0.5 \mu \mathrm{M}$ soybean trypsin inhibitor) [16]. Microsomal vesicles were isolated from hind limb muscle homogenates by a method previously optimized in our laboratory [17]. Freshly dissected tissues from normal adult white New Zealand rabbits and from normal and dystrophic mdx/y mice were obtained through the Biomedical Facility, University College Dublin. The protein concentration of isolated microsomes was determined according to Bradford [18] using myofibrillar proteins as a standard.

\section{Continuous-elution gel electrophoresis}

Microsomal muscle proteins were isolated by continuous-elution gel electrophoresis using a cylindrical preparative polyarylamide gel electrophoresis unit from Bio-Rad Laboratories (Hemel Hempstead, Hertrshire, UK) $[19,20]$. Electrophoresis was performed according to the denaturing discontinuous buffer system of Laemmli [21]. The Model 491 Prep Cell was run with a BioRad Power Pac 1000 and eluted fractions were collected with a EP-1 Econo pump and Model 2128 Fraction Collector. Since gel tube width, length, and pore size are three important variables for sample separation [19], a series of optimization runs was performed under varying conditions. Routinely, preparative electrophoresis was performed with $7 \%(\mathrm{w} / \mathrm{v})$ resolving gels that had been prepared in the casting stand at a $7-\mathrm{cm}$ height setting with a $28-\mathrm{mm}$-diameter gel assembly tube. A 5\% (w/v) stacking gel was used whereby the quantity of the stacking system was required to be at least twice that of the sample volume to be loaded. Attachment of the polymerized gel tube assembly to the elution chamber containing the elution frit, dialysis membrane, and support frit, filling of the upper and lower buffer chambers with a standard running buffer system and proper connecting to the buffer recirculation pump (flow rate of $80 \mathrm{ml} / \mathrm{min}$ ), the peristaltic pump, and the automated fraction collector were carried out according to the manufacturer's instructions. The muscle membrane preparation $(20 \mathrm{mg}$ protein/ml) was diluted 1:1 with a 
reducing sample buffer $(125 \mathrm{mM}$ Tris- $\mathrm{Cl}, \mathrm{pH} 6.8,20 \%$ (v/v) glycerol, 20\% (w/v) sucrose, $0.002 \%(\mathrm{w} / \mathrm{v})$ bromophenol blue, 3\% (w/v) SDS, $75 \mathrm{mM}$ dithiothreitol) and the solubilized sample then carefully loaded onto the preparative gel system and electrophoresed through the cylindrical matrix using standard conditions $(12 \mathrm{~W}$, $45 \mathrm{~mA}, 270 \mathrm{~V})$. Once the dye front had run off the gel, which takes approximately $4 \mathrm{~h}$, isolated proteins were drawn through the dialysis membrane and frits into the cooling core by the peristaltic pump at a rate of $1 \mathrm{ml} /$ $\mathrm{min}$. Eluted proteins were collected in $2.5 \mathrm{-ml}$ fractions. In a typical run, 130 fractions were collected over a time period of approximately $5 \mathrm{~h}$. Millipore filter units were used to concentrate fractions 25 -fold prior to silver staining and immunoblot analysis. Eluted samples containing a protein of interest were evaluated for overlap with other microsomal elements of similar molecular mass and then fractions representing a specific protein species were pooled. Since the presence of excess sodium dodecyl sulfate would interfere with both conjugation reactions and detailed studies of potential protein-protein interactions, the ionic detergent was removed by initially dialyzing samples overnight against distilled water using a Slide-A-Lyzer dialysis cassette system followed by precipitation with the Pierce SDS-OUT Precipitation kit. Calsequestrin of apparent $63 \mathrm{kDa}$ was usually eluted in fractions 28 to 34 . To demonstrate that differential blot overlays can be performed, we also isolated the junctional protein triadin of apparent $95 \mathrm{kDa}$, which was usually present in fractions 44 to 48 . To avoid contamination with abundant proteins such as the $110-\mathrm{kDa} \mathrm{Ca}^{2+}-$ ATPases, triadin was first preselected by immunoprecipitation. Since monoclonal antibody VIIID $1_{2}$ to calsequestrin coimmunoprecipitates triadin, as previously demonstrated by our laboratory [14], we first isolated the supramolecular triad complex by this method and then separated the precipitated proteins by continuous-elution gel electrophoresis. Fractions containing triadin without contaminants were identified by silver staining and immunoblotting.

\section{Blot overlay assay}

To demonstrate the usefulness of continuous-elution gel electrophoresis as a preparative tool for the isolation of individual proteins that can then be employed in blot overlay techniques, we have isolated calsequestrin and triadin by this method. The electrophoretically separated microsomal proteins were conjugated to an amine-reactive horseradish peroxidase marker enzyme according to the manufacturer's instructions in the Pierce EZ-Link Plus Activated Peroxidase Kit. Labeled calsequestrin was then used as a ligand to detect potential protein binding to the nitrocellulose-immobilized microsomal fraction, as recently described in detail
$[4,14,15]$. Nitrocellulose sheets representing replicas of electrophoretically separated microsomal proteins were blocked for $2 \mathrm{~h}$ in $0.15 \mathrm{M} \mathrm{NaCl}, 50 \mathrm{mM}$ Tris-Cl, $\mathrm{pH} 7.5$, $0.05 \%(\mathrm{v} / \mathrm{v})$ Tween 20 and then incubated for $1 \mathrm{~h}$ with the peroxidase-calsequestrin probe [14]. Following several washing steps, the protein decoration was visualized by enhanced chemiluminescence [22]. Densitometric scanning of enhanced chemiluminescence blots was performed on a Molecular Dynamics 300S computing densitometer (Sunnyvale, CA) with ImageQuant V3.0 software. To demonstrate the specificity of proteinprotein interactions, essential control experiments were performed. Blot overlay assays were carried out in the presence of $1 \%(\mathrm{w} / \mathrm{v})$ sodium dodecyl sulfate or $1 \%(\mathrm{v} / \mathrm{v})$ Triton X-100. Furthermore, blots were preincubated with monoclonal antibody VIIID1 2 prior to incubation with the peroxidase-conjugated calsequestrin or the calsequestrin probe itself was pretreated with the antibody for $1 \mathrm{~h}$ prior to application to the nitrocellulose sheet.

\section{Gel electrophoresis and immunoblot analysis}

Electrophoretic separation of microsomal proteins by standard sodium dodecyl sulfate polyacrylamide gel procedures [21] was performed with a Mini-MP3 system from Bio-Rad Laboratories. Routinely, 7\% (w/v) resolving gels were used and $20 \mu \mathrm{g}$ protein was loaded per lane [17]. Gels were stained with Coomassie blue or silver or transferred onto Immobilon NC membranes according to Towbin et al. [23]. Blocking, washing, and incubation of nitrocellulose replicas with primary and secondary peroxidase-conjugated antibodies was carried out by standard methods [16]. The following primary antibodies were used (monoclonal antibody (mAb); ${ }^{1}$ polyclonal antibody (pAb)) mAb 88B to the $\delta$ subunit of the nicotinic acetylcholine receptor; $\mathrm{mAb}$ IIH11 to the fast $\mathrm{Ca}^{2+}$-ATPase isoform SERCA1, mAb IID8 to the slow $\mathrm{Ca}^{2+}$-ATPase isoform SERCA2, mAb VIIID1 $1_{2}$ to clasequestrin, mAb 374 to glyceraldehyde-3-phosphate dehydrogenase, mAb NCL-b-DG to $\beta$-dystroglycan, $\mathrm{pAb}$ to junctin (generous gift from Dr. Steven Cala, Wayne State University, Detroit, MI), mAb c464.6 to the $\alpha$ subunit of the $\mathrm{Na}^{+} / \mathrm{K}^{+}-$ATPase, mAb $34 \mathrm{C}$ to the $\mathrm{RyR} 1$ isoform of the ryanodine receptor $\mathrm{Ca}^{2+}$-release channel, mAb IIG12 to triadin, and mAb 20A to the $\alpha_{2}$ subunit of the dihydropyridine receptor. Immunodecorated protein bands were visualized by the enhanced chemiluminescence method [22] and densitometric scanning was carried out with a Molecular Dynamics 300S computing densitometer.

\footnotetext{
${ }^{1}$ Abbreviations used: $\mathrm{mAb}$, monoclonal antibody; pAb, polyclonal antibody.
} 


\section{Results and discussion}

Although monomeric muscle proteins are capable of performing complex reaction cycles, many physiologically important components do not exist in isolation under native conditions [24]. Therefore, if one considers individual proteins as the basic units of the proteome, protein complexes actually form the functional units of cell biology. This gives biochemical investigations into the supramolecular structure of membrane complexes a central place in biological research. Here, we have used continuous-elution gel electrophoresis to isolate the microsomal muscle protein calsequestrin to homogeneity and then used it as a peroxidase-conjugated probe in a blot overlay technique. Our analysis encompassed the demonstration of successful protein separation using preparative gel electrophoresis (Fig. 1a), the identification of separated muscle proteins (Figs. $1 \mathrm{~b}$ and 2), the peroxidase conjugation of electrophoretically purified calsequestrin (Fig. 3), the evaluation of the specificity of
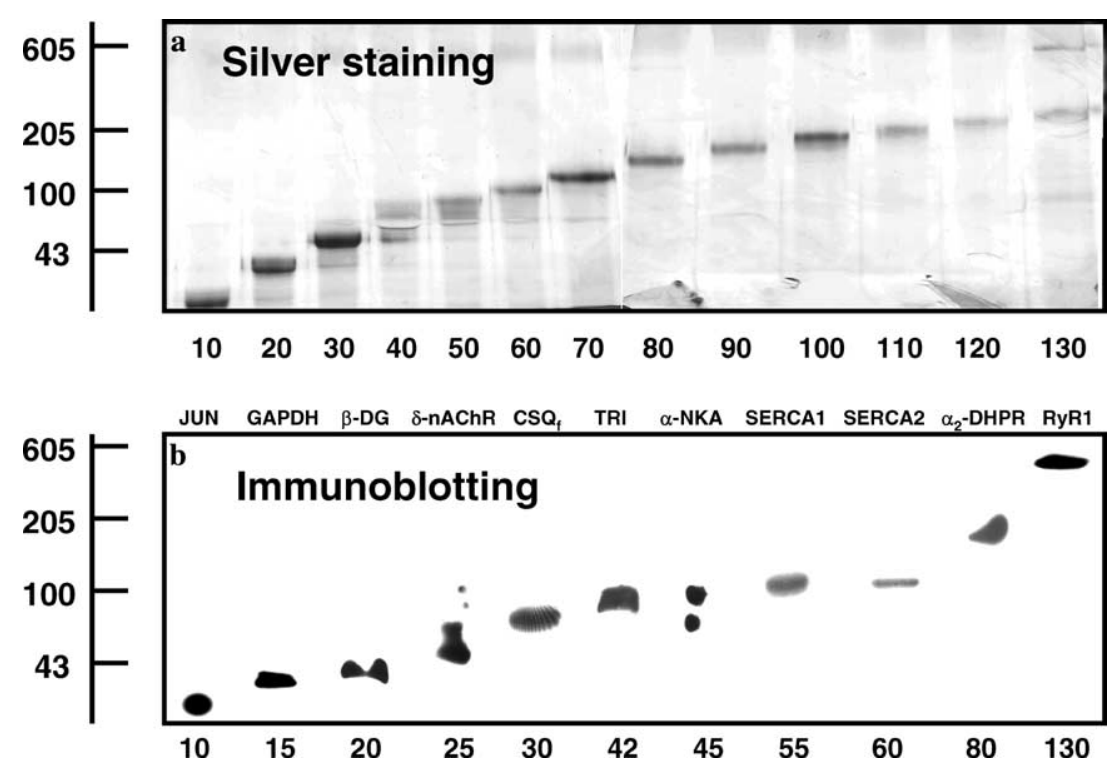

Fig. 1. Continuous-elution gel electrophoresis of muscle microsomes. Shown is a silver-stained gel (a) and corresponding immunoblots (b) of selected $2.5-\mathrm{ml}$ fractions eluted from a 7\% (w/v) preparative gel (prepared with a 7-cm height setting and a $28-\mathrm{mm}$ diameter gel assembly tube). In (b), the presence of marker proteins is visualized by immunodecoration with antibodies to junctin (JUN), glyceraldehyde-3-phosphate dehydrogenase (GAPDH), $\beta$-dystroglycan ( $\beta$-DG), the $\delta$ subunit of the nicotinic acetylcholine receptor ( $\delta$-nAChR), fast calsequestrin (CSQ), triadin (TRI), the $\alpha$ subunit of the $\mathrm{Na}^{+} / \mathrm{K}^{+}-$ATPase $\left(\alpha\right.$-NKA), the fast $\mathrm{Ca}^{2+}-$ ATPase isoform SERCA1, the slow $\mathrm{Ca}^{2+}-\mathrm{ATPase}$ isoform SERCA2, the $\alpha_{2}$ subunit of the dihydropyridine receptor $\left(\alpha_{2}\right.$-DHPR), and the RyR1 isoform of the ryanodine receptor $\mathrm{Ca}^{2+}$-release channel. Fraction numbers are marked below the gel and immunoblots. Sizes of molecular mass standards (in $\mathrm{kDa}$ ), as deduced from rat myofibrillar proteins, are indicated on the left.

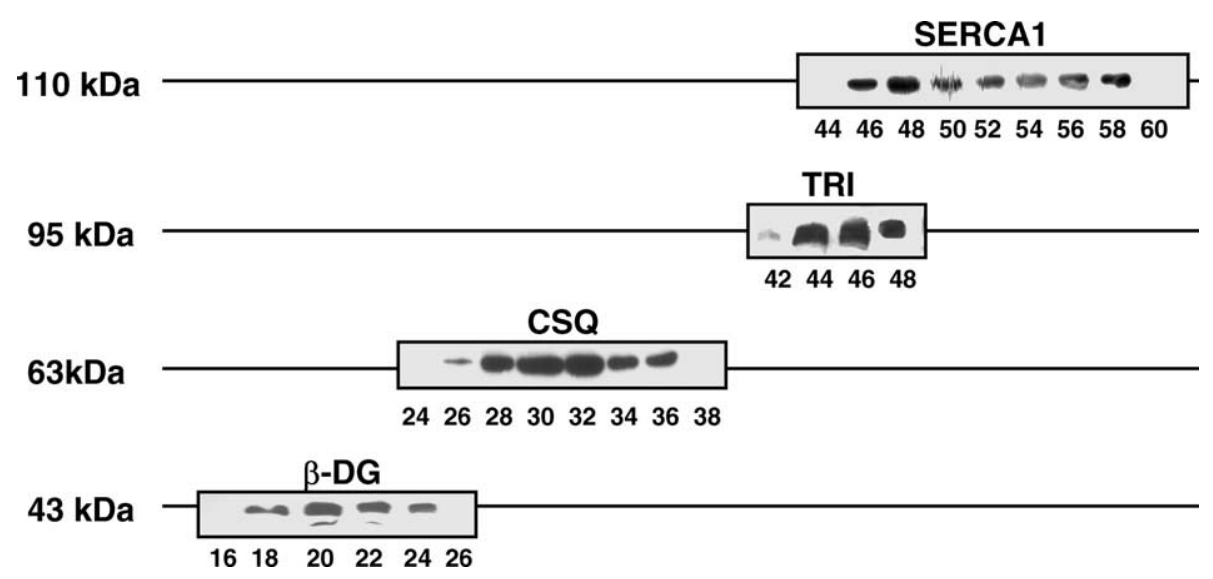

Fig. 2. Isolation of calsequestrin by continuous-elution gel electrophoresis. Shown are immunoblots of fractions containing the fast $\mathrm{Ca}^{2+}-\mathrm{ATPase}$ isoform SERCA1 of apparent $110 \mathrm{kDa}$, triadin (TRI) of apparent $95 \mathrm{kDa}$, calsequestrin (CSQ) of apparent $63 \mathrm{kDa}$, and $\beta$-dystroglycan ( $\beta$-DG) of apparent $43 \mathrm{kDa}$. Calsequestrin-containing fractions that did not exhibit an overlap with other muscle marker proteins were pooled, re-electrophoresed, and analyzed by Coomassie staining prior to peroxidase conjugation (see Fig. 3). 


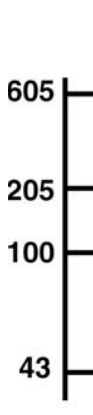

CB

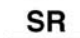

CB

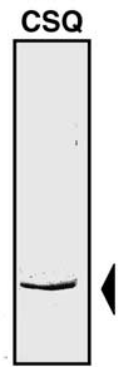

2

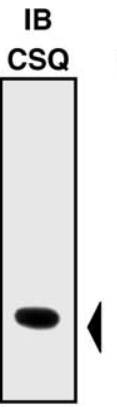

3
IB

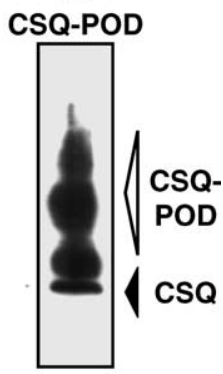

4

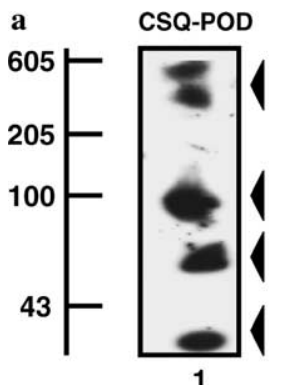

1

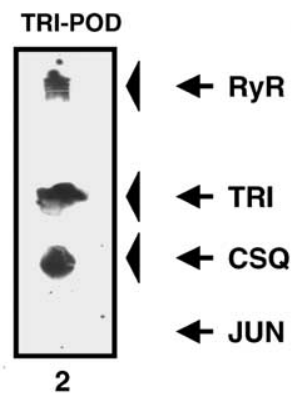

b

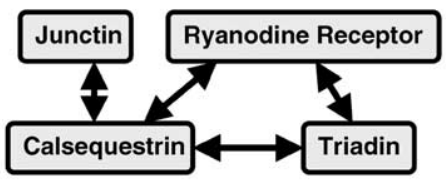

c

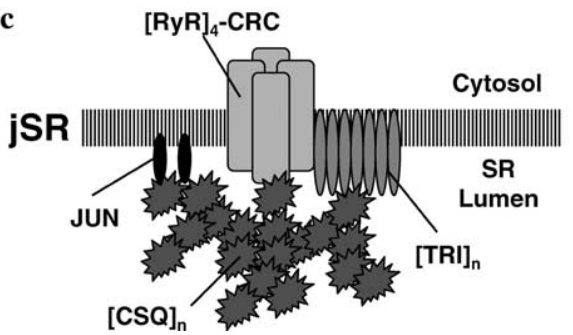

Fig. 5. Differential blot overlay analysis. To comparatively illustrate protein-protein interactions within the supramolecular triad complex from skeletal muscle, the overlay with a peroxidase-conjugated calsequestrin (CSQ-POD) probe (lane 1) and a peroxidase-conjugated triadin (TRI-POD) probe (lane 2) is shown in (a). The positions of decorated protein bands are marked by arrow heads and the positions of the four main triad complex components, the ryanodine receptor (RyR), triadin (TRI), calsequestrin (CSQ), and junctin (JUN) are indicated by arrows. Sizes of molecular mass standards (in kDa), as deduced from rat myofibrillar proteins, are indicated on the left. In (b) is shown a diagram of the intermolecular linkage between sarcoplasmic reticulum elements as deduced from differential blot overlay analysis. In (c) are shown the possible spatial arrangement of the junctional sarcoplasmic reticulum (jSR) and the position of luminal calsequestrin clusters of the terminal cisternae in relation to triadin, junctin, and the ryanodine receptor $\mathrm{Ca}^{2+}$-release channel (CRC) tetramer.

wide range of differently sized proteins from skeletal muscle microsomes. The silver-stained gel of reelectrophoresed fractions portrays a representative elution profile and clearly shows an increase in the relative molecular mass of proteins during the elution process (Fig. 1a). As illustrated in the immunoblot analysis of selected fractions in Fig. 1b, a successful separation of proteins ranging from approximately 20 to $600 \mathrm{kDa}$ was achieved. Proteins with a relative molecular mass below $50 \mathrm{kDa}$, such as junctin, glyceraldehyde-3-phosphate dehydrogenase, and $\beta$-dystroglycan were eluted according to their size in the first quarter of collected fractions. By contrast, muscle markers ranging from apparent 50 to $110 \mathrm{kDa}$, such as the $\delta$ subunit of the nicotinic acetylcholine receptor, the fast calsequestrin, the $\alpha$ subunit of the $\mathrm{Na}^{+} / \mathrm{K}^{+}-$ATPase, the fast $\mathrm{Ca}^{2+}$ ATPase isoform SERCA1, and the slow $\mathrm{Ca}^{2+}$-ATPase 
a Normal mouse muscle

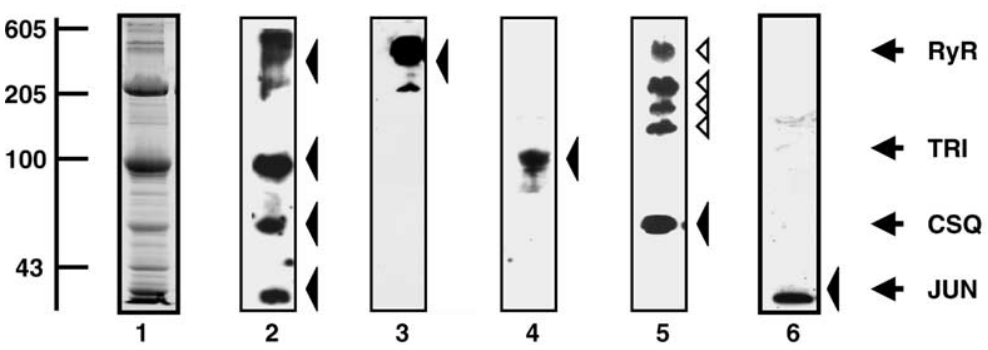

b Dystrophic max mouse muscle
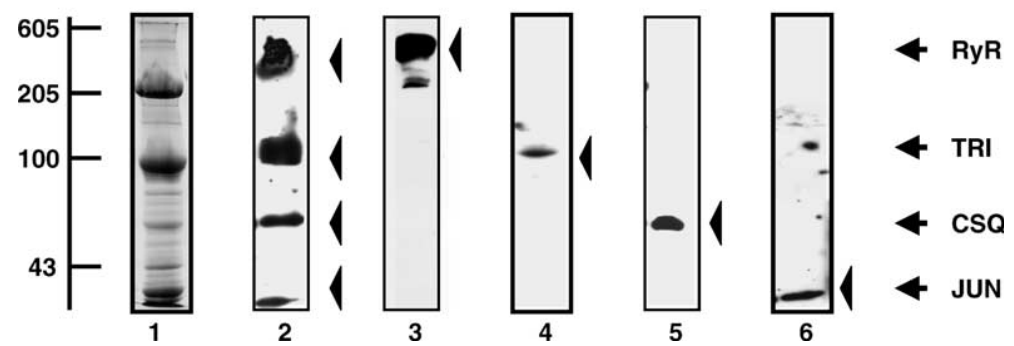

Fig. 6. Comparative blot overlay analysis of dystrophic specimens. Shown are Coomassie-stained gels (lane 1), calsequestrin blot overlays (lane 2), and immunoblots (lanes 3-6) of microsomes from normal (a) and dystrophic mdx (b) mouse skeletal muscle. Lanes 3 to 6 were immunodecorated with antibodies to the ryanodine receptor, triadin, calsequestrin, and junctin, respectively. The positions of decorated protein bands are marked by closed arrow heads and the positions of the four main triad complex components, the ryanodine receptor (RyR), triadin (TRI), calsequestrin (CSQ), and junctin (JUN), are indicated by arrows. In lane 5 in (a), the positions of four calsequestrin-like proteins of high molecular mass are marked by open arrow heads. These calsequestrin isoforms are absent from dystrophic fibers in lane 5 in (b). Sizes of molecular mass standards (in kDa), as deduced from rat myofibrillar proteins, are indicated on the left.

isoform SERCA2, were eluted according to their size in the second quarter of collected fractions. A muscle membrane element exhibiting an electrophoretic mobility in the molecular range of 140 to $170 \mathrm{kDa}$ is represented by the $\alpha_{2}$ subunit of the dihydropyridine receptor. This transverse-tubular protein was eluted in the third quarter of collected fractions. The muscle marker with the highest molecular mass investigated was the RyR1 isoform of the ryanodine receptor $\mathrm{Ca}^{2+}$-release channel. This protein of $565 \mathrm{kDa}$ was eluted according to its size in the last quarter of fractions obtained by continuous-elution gel electrophoresis.

Isolation of calsequestrin by continuous-elution gel electrophoresis

Although the immunoblot analysis presented in Fig. $1 \mathrm{~b}$ gives an overview of the positions of various marker proteins in eluted fractions, it does not account for the potential overlap patterns of individual protein species. For a successful separation of a protein of interest by the continuous-elution gel electrophoresis technique, the starting material has to be void of abundant protein molecules exhibiting a similar relative molecular mass. Using a 7-cm gel system, prepared with a $28-\mathrm{mm}$-diameter gel assembly tube, it was possible to elute calsequestrin-containing fractions essentially void of major contaminants. The elution profile of abundant micro- somal proteins such as $\beta$-dystroglycan of apparent $43 \mathrm{kDa}$, triadin of apparent $95 \mathrm{kDa}$, and the fast $\mathrm{Ca}^{2+}$ ATPase isoform SERCA1 of apparent $110 \mathrm{kDa}$ did not overlap with that of calsequestrin (Fig. 2). The various $50-\mathrm{kDa}$ subunits of the nicotinic acetylcholine receptor represent only low-abundance microsomal proteins and they did not elute in the higher fraction numbers containing calsequestrin (not shown).

\section{Preparation of peroxidase-conjugated calsequestrin}

Prior to conjugation to peroxidase, the homogeneity of isolated calsequestrin derived from pooled preparative gel electrophoresis fractions was demonstrated by Coomassie staining. Compared to the main protein bands visualized in electrophoretically separated microsomes, the calsequestrin preparation exhibits only one major band of approximately $63 \mathrm{kDa}$ (Fig. 3). This protein is clearly recognized by monoclonal antibody $\mathrm{VIIID}_{2}$ as the fast isoform of skeletal muscle calsequestrin (Fig. 3). As illustrated in lane 4 of Fig. 3, following incubation with the marker enzyme peroxidase, the relative molecular mass of the majority of calsequestrin-containing bands shifted to a position of lower electrophoretic mobility. This demonstrated a successful conjugation between purified calsequestrin and peroxidase. 


\section{Specificity of the calsequestrin blot overlay assay}

Following peroxidase conjugation, the calsequestrin probe was used in the blot overlay analysis of microsomal membranes. As with almost all labeling procedures, modifications of the target protein may induce conformational changes that potentially interfere with subsequent analytical approaches. In the case of the peroxidase-calsequestrin probe, the conjugation of the marker enzyme might possibly inhibit sensitive protein interactions. However, the isolated terminal cisternae element formed stable interactions reproducibly with four nitrocellulose-immobilized protein bands (Fig. 4). This result agreed with previous overlay assays performed with calsequestrin which had been isolated by conventional chromatography [14]. The fact that incubation with the two different calsequestrin probes resulted in the same overlay binding pattern demonstrates that biological binding affinities are retained in electrophoretically prepared muscle proteins. Comparative immunoblotting has identified the microsomal calsequestrin-binding proteins as the RyR 1 isoform of the $\mathrm{Ca}^{2+}$-release channel of apparent $565 \mathrm{kDa}$, triadin monomers of $94 \mathrm{kDa}$, fast calsequestrin of approximately $63 \mathrm{kDa}$, and junctin of apparent $26 \mathrm{kDa}$ [15]; this is also illustrated in Fig. 6. To show how specific overlay assays are, we have performed essential control experiments. While the incubation of nitrocellulose replicas of microsomes with antibodies to calsequestrin specifically eliminated the labeling of the $63-\mathrm{kDa}$ protein band, the staining pattern of the other three triad proteins was only marginally altered (Fig. 4). Pretreatment of the calsequestrin probe with an antibody to itself clearly abolished the labeling of all four bands (Fig. 4). Hence, antibody binding to membrane-bound calsequestrin or the calsequestrin conjugate triggers steric hindrance to eliminate successful self-aggregation or proper coupling between the terminal cisternae protein and other triad components. In addition, calsequestrin blot overlay assays were carried out in the presence of the ionic detergent sodium dodecyl sulfate and the nonionic detergent Triton X-100. In agreement with previous studies [14], the detergents eliminated the labeling of the triad bands by the calsequestrin probe (Fig. 4). These four control experiments clearly demonstrated the high degree of specificity of the blot overlay binding pattern.

\section{Differential blot overlay analysis}

Since calsequestrin overlays performed with a protein originally isolated by continuous-elution gel electrophoresis were shown to be specific, we were interested in evaluating a differential approach of the overlay technique. Since it is well established that the junctional muscle triad complex consists of four main constituents, this muscle membrane assembly is a suitable system to assess novel protein binding assays for the visualization of quaternary protein structures. As illustrated in Fig. $5 \mathrm{a}$, the overlay pattern of peroxidase-conjugated calsequestrin and peroxidase-conjugated triadin clearly differed. The terminal cisternae $\mathrm{Ca}^{2+}$-binding protein clearly interacted with junctin, the ryanodine receptor, triadin, and itself, while the junctional element of $95 \mathrm{kDa}$ formed self-aggregates and a linkage to the $\mathrm{Ca}^{2+}$-release channel and calsequestrin, but not to the calsequestrin-binding protein junctin. This agrees with previous biochemical studies by Guo and Campbell [25] who could demonstrate that triadin mediates as a linker between the junctional $\mathrm{Ca}^{2+}$-release channel units and the major luminal $\mathrm{Ca}^{2+}$-reservoir complex. As shown above in Fig. 2, there is a considerable overlap in the elution profile between the triadin of apparent $95 \mathrm{kDa}$ and the highly abundant fast $\mathrm{Ca}^{2+}-$ ATPase isoform SERCA1 of apparent $110 \mathrm{kDa}$. We could therefore not isolate triadin from microsomal membranes but had to preselect for this junctional element by immunoprecipitation prior to preparative gel electrophoresis. This alternative strategy overcame the contamination of triadin preparation with the sarcoplasmic reticulum $\mathrm{Ca}^{2+}$ pumps and yielded a high enough protein concentration to produce a peroxidase-conjugated triadin probe. The diagrammatic representations in Figs. $5 \mathrm{~b}$ and $\mathrm{c}$ summarize the conclusion that one can draw from the differential overlay pattern using the two different probes. Calsequestrin seems to interact with all four central elements of triadic signal transduction: (i) it forms selfaggregates that exhibit cooperative kinetics with respect to ion binding [26], (ii) it is stabilized by interactions with junctin [27], and (iii) it communicates with $\mathrm{Ca}^{2+}$. release units indirectly via triadin [25] and directly by coupling to the ryanodine receptor [28]. This shows that membrane-associated proteins can be isolated by preparative gel electrophoresis without loosing their biological binding affinities and that they can be successfully employed as peroxidase-conjugated probes in differential overlay blot analyses.

\section{Comparative blot overlay analysis of dystrophic speci- mens}

Blot overlay assays suggest themselves as biomedical tools for the differential screening of potential abnormalities in protein-protein interactions. They might be employed in the evaluation of impaired protein linkage triggered by pathophysiological changes. In muscular dystrophy, ion flux through surface $\mathrm{Ca}^{2+}$-leak channels is responsible for an elevated $\mathrm{Ca}^{2+}$-dependent net degradation of muscle proteins; abnormal $\mathrm{Ca}^{2+}$ cycling through the lumen of the sarcoplasmic reticulum and mitochondria is also involved in the muscular degeneration process [29]. We therefore employed the novel calsequestrin probe in the comparative analysis of nor- 
mal versus dystrophic microsomes. Fig. 6a illustrates the blot overlay analysis of normal mouse muscle membranes with the labeling of the four main triad components. Comparative immunoblotting identified them as the ryanodine receptor, triadin, calsequestrin, and junctin. In addition to the $63-\mathrm{kDa}$ monomeric calsequestrin band, four high-molecular-mass bands are recognized by the monoclonal antibody to calsequestrin (Fig. 6a). These ion-binding elements are named calsequestrin-like proteins and are missing in muscular dystrophy (Fig. 6b), as has previously been reported [30]. The blot overlay analysis of dystrophic microsomes did not reveal a drastic difference in the binding pattern of peroxidase-conjugated calsequestrin. Thus, the underlying mechanism of abnormal $\mathrm{Ca}^{2+}$ homeostasis in muscular dystrophy does not appear to involve impaired triad complex formation. Overall this analysis shows that the blot overlay technique can be useful in the differential analysis of pathological samples.

\section{Future proteomics applications of blot overlay techniques}

As outlined in the flow chart of Fig. 7, preparative gel electrophoresis can be employed to isolate a protein of interest and then use it as a peroxidase-conjugated probe in blot overlays. Continuous-elution gel electrophoresis can separate a wide range of differently sized proteins from subcellular fractions. This report illustrates that in the case of skeletal muscle microsomes, individual proteins exhibiting a relative molecular mass of 20 to $600 \mathrm{kDa}$ can be isolated by a single preparative gel run. In the case of overlapping elution profiles, preselection of specific protein species can be performed by immunoprecipitation followed by preparative electrophoresis. Our study indicates that continuous-elution gel electrophoresis may be applied for the rapid identification of protein-protein interactions in future high-throughput approaches to analyze protein complex formation within subproteomes or proteomes. Since supramolecular membrane assemblies, and not individual proteins or peptides, often represent the native configuration that performs biological functions, proteome research will have to evolve from the initial identification and protein cataloging stage to a comprehensive functional analysis. In addition to a global determination of protein abundance and post-translational modifications, an important goal will be the elucidation of complex networks of interaction patterns between the individual elements of a protein complement. Since orders of magnitude in expression levels exist between different proteins, this will not be a trivial undertaking, probably making the parallel analysis of subproteomes a necessity. In this respect, this study sets the scene for the global intraproteomic network analysis of protein complex formation, having demonstrated that continuous-elution gel electrophoresis is a suitable preparative tool and blot

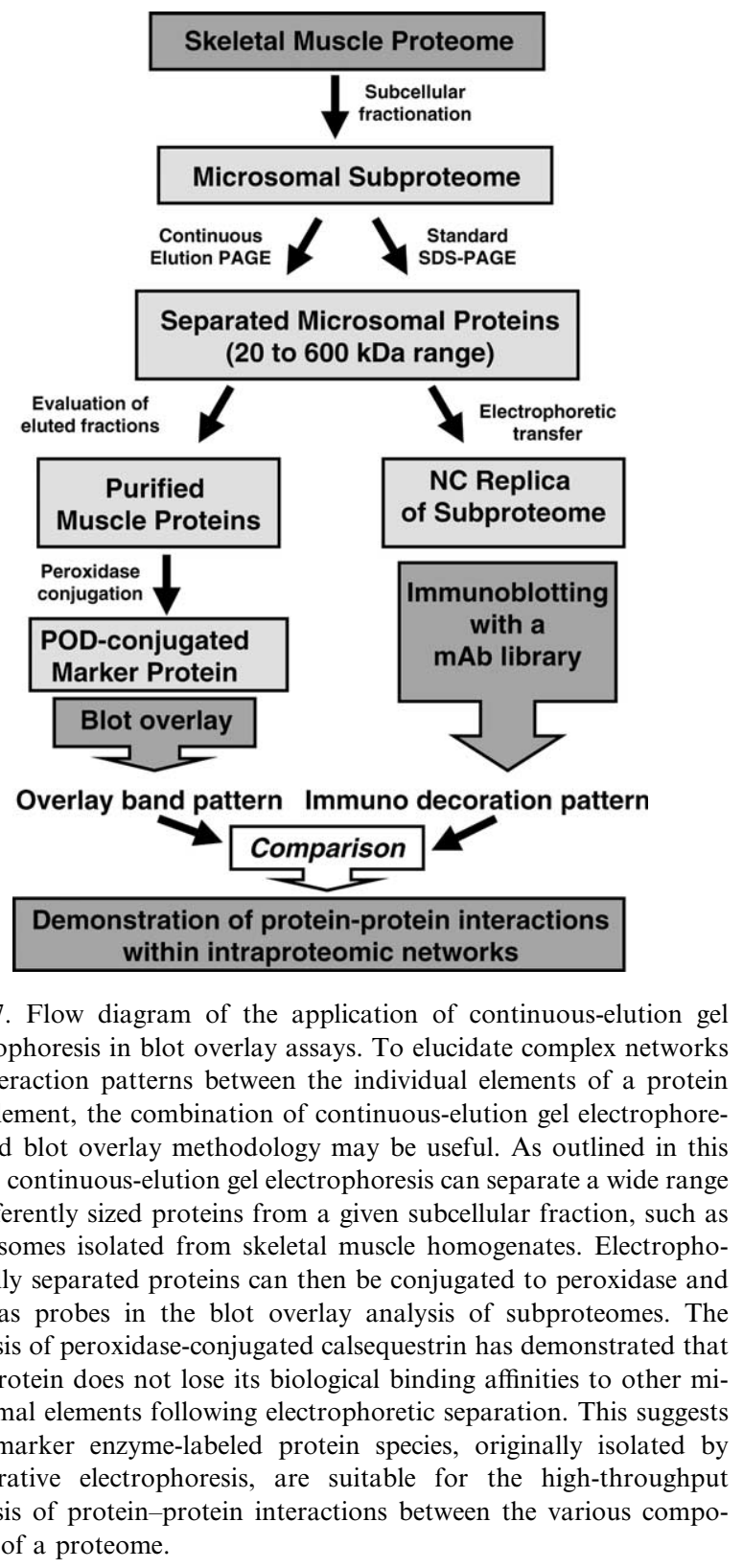

overlay assays represent a convenient method for the direct visualization of protein oligomerization.

\section{Acknowledgments}

The authors thank Dr. Steven Cala for his generous gift of antibodies and Mr. Eoin Cummins for expert technical assistance. Research was funded by a postgraduate support grant from Enterprise Ireland to C.M. and project grants from the Irish Health Research Board, Muscular Dystrophy Ireland, and the European Commission (RTN2-2001-00337) to K.O. The purchase of the preparative gel electrophoresis unit was supported 
by the President's Research Award of the National University of Ireland, Dublin.

\section{References}

[1] L. Kremer, J.E. Dominguez, J. Avila, Detection of tubulinbinding proteins by an overlay assay, Anal. Biochem. 175 (1988) 91-95.

[2] T. Mehlman, W.H. Burgess, Detection and characterization of heparin-binding proteins with a gel overlay procedure, Anal. Biochem. 188 (1990) 159-163.

[3] A.L. Hitt, S.D. Laing, S. Olson, Development of a fluorescent Factin blot overlay assay for detection of $\mathrm{F}$-actin binding proteins, Anal. Biochem. 310 (2002) 67-71.

[4] L. Glover, G. Froemming, K. Ohlendieck, Calsequestrin blot overlay of two-dimensional electrophoretically separated microsomal proteins from skeletal muscle, Anal. Biochem. 299 (2001) 268-271.

[5] L.M. Veenhoff, E.H. Heuberger, B. Poolman, Quaternary structure and function of transport proteins, Trends Biochem. Sci. 27 (2002) 242-249.

[6] V. Helms, Attraction within the membrane: forces behind transmembrane protein folding and supramolecular complex assembly, EMBO Rep. 3 (2002) 1133-1138.

[7] I.T. Arkin, Structural aspects of oligomerization taking place between the transmembrane alpha-helices of bitopic membrane proteins, Biochim. Biophys. Acta 1565 (2002) 347-363.

[8] H. Stark, Three-dimensional electron cryomicroscopy of ribosomes, Curr. Protein Pept. Sci. 3 (2002) 79-91.

[9] T. Wagenknecht, M. Samso, Three-dimensional reconstruction of ryanodine receptors, Front. Biosci. 7 (2002) D1464-D1474.

[10] T. Wagenknecht, M. Radermacher, Ryanodine receptors: structure and macromolecular interactions, Curr. Opin. Struct. Biol. 7 (1997) 258-265.

[11] M. Fill, J.A. Copello, Ryanodine receptor calcium release channels, Physiol. Rev. 82 (2002) 893-922.

[12] C. Franzini-Armstrong, A.O. Jorgensen, Structure and development of $\mathrm{E}-\mathrm{C}$ coupling units in skeletal muscle, Annu. Rev. Physiol. 56 (1994) 509-534.

[13] B.E. Murray, G.R. Froemming, P.B. Maguire, K. Ohlendieck, Excitation-contraction-relaxation cycle: role of $\mathrm{Ca}^{2+}$-regulatory membrane proteins in normal, stimulated and pathological skeletal muscle (review), Int. J. Mol. Med. 1 (1998) 677-687.

[14] L. Glover, K. Culligan, S. Cala, C. Mulvey, K. Ohlendieck, Calsequestrin binds to monomeric and complexed forms of key calcium-handling proteins in native sarcoplasmic reticulum membranes from rabbit skeletal muscle, Biochim. Biophys. Acta 1515 (2001) 120-132.

[15] L. Glover, S. Quinn, M. Ryan, D. Pette, K. Ohlendieck, Supramolecular calsequestrin complex, Eur. J. Biochem. 269 (2002) 4607-4616.
[16] B.E. Murray, K. Ohlendieck, Cross-linking analysis of the ryanodine receptor and alpha1-dihydropyridine receptor in rabbit skeletal muscle triads, Biochem. J. 324 (1997) 689-696.

[17] S. Harmon, G.R. Froemming, E. Leisner, D. Pette, K. Ohlendieck, Low-frequency stimulation of fast muscle affects the abundance of $\mathrm{Ca}^{2+}$-ATPase but not its oligomeric status, J. Appl. Physiol. 90 (2001) 371-379.

[18] M.M. Bradford, A rapid and sensitive method for the quantitation of microgram quantities of protein utilizing the principle of protein-dye binding, Anal. Biochem. 72 (1976) 248-254.

[19] M.J. Treuheit, A. Ataei, E.T. Wallick, T.L. Kirley, Purification of the alpha and beta subunits of $\mathrm{Na}^{+}, \mathrm{K}^{+}$-ATPase by continuous elution electrophoresis, Prep. Biochem. 23 (1993) 375-387.

[20] P. Balagopal, K.S. Nair, W.S. Stirewalt, Isolation of myosin heavy chain from small skeletal muscle samples by preparative continuous elution gel electrophoresis: application to measurement of synthesis rate in human and animal tissue, Anal. Biochem. 221 (1994) 72-77.

[21] U.K. Laemmli, Cleavage of structural proteins during the assembly of the head of bacteriophage T4, Nature 227 (1970) 680-685.

[22] S.J. Bradd, M.J. Dunn, Analysis of membrane proteins by Western blotting and enhanced chemiluminescence, Methods Mol. Biol. 19 (1993) 211-218.

[23] H. Towbin, T. Staehelin, J. Gordon, Electrophoretic transfer of proteins from polyacrylamide gels to nitrocellulose sheets: procedure and some applications, Proc. Natl. Acad. Sci. USA 76 (1979) $4350-4354$.

[24] D.L. Stokes, T. Wagenknecht, Calcium transport across the sarcoplasmic reticulum: structure and function of $\mathrm{Ca}^{2+}-$ ATPase and the ryanodine receptor, Eur. J. Biochem. 267 (2000) 5274 5279 .

[25] W. Guo, K.P. Campbell, Association of triadin with the ryanodine receptor and calsequestrin in the lumen of the sarcoplasmic reticulum, J. Biol. Chem. 270 (1995) 9027-9030.

[26] M. Tanaka, T. Ozawa, A. Maurer, J.D. Cortese, S. Fleischer, Apparent cooperativity of $\mathrm{Ca}^{2+}$-binding associated with crystallization of $\mathrm{Ca}^{2+}$-binding protein from sarcoplasmic reticulum, Arch. Biochem. Biophys. 251 (1986) 369-378.

[27] L. Zhang, J. Kelley, G. Schmeisser, Y.M. Kobayashi, L.R. Jones, Complex formation between junctin, triadin, calsequestrin, and the ryanodine receptor. Proteins of the cardiac junctional sarcoplasmic reticulum membrane, J. Biol. Chem. 272 (1997) 2338923397.

[28] B.E. Murray, K. Ohlendieck, Complex formation between calsequestrin and the ryanodine receptor in fast- and slow-twitch rabbit skeletal muscle, FEBS Lett. 429 (1998) 317-322.

[29] K. Culligan, K. Ohlendieck, Abnormal calcium handling in muscular dystrophy, Bas. Appl. Myol. 12 (2002) 147-157.

[30] K. Culligan, N. Banville, P. Dowling, K. Ohlendieck, Drastic reduction of calsequestrin-like proteins and impaired calcium binding in dystrophic mdx muscle, J. Appl. Physiol. 92 (2002) 435-445. 